\title{
CPC-containing oral rinses inactivate SARS-CoV-2 variants and are active in the presence of human saliva
}

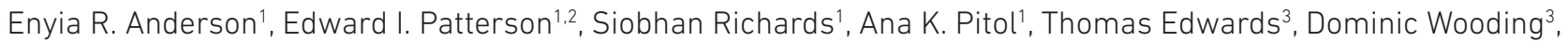 \\ Kate Buist ${ }^{3}$, Alison Green ${ }^{4}$, Sayandip Mukherjee ${ }^{5}$, Michael Hoptroff ${ }^{4, *}$ and Grant L. Hughes ${ }^{1, *}$
}

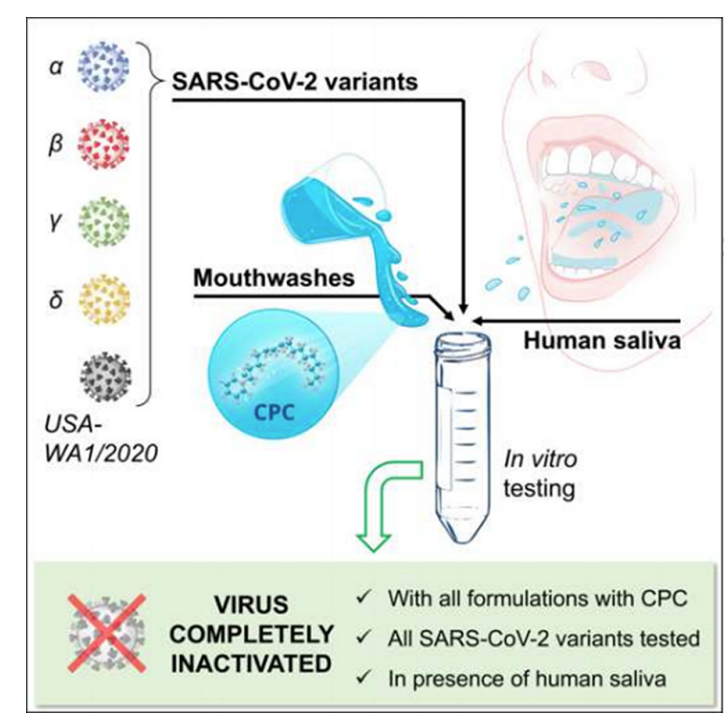

\section{Graphical abstract}

Inactivation of SARS-CoV-2 variants by oral mouthwashes containing $0.07 \%$ cetyl pyridinium chloride (CPC).

\begin{abstract}
Introduction. The importance of human saliva in aerosol-based transmission of SARS-CoV-2 is now widely recognized. However, little is known about the efficacy of virucidal mouthwash formulations against emergent SARS-CoV-2 variants of concern and in the presence of saliva.

Hypothesis. Mouthwashes containing virucidal actives will have similar inactivation effects against multiple SARS-CoV-2 variants of concern and will retain efficacy in the presence of human saliva.
\end{abstract}

Aim. To examine in vitro efficacy of mouthwash formulations to inactivate SARS-CoV-2 variants.

Received 26 October 2021; Accepted 06 January 2022; Published 18 February 2022

Author affiliations: 'Liverpool School of Tropical Medicine, Departments of Vector Biology and Tropical Disease Biology, Centre for Neglected Tropical Diseases, Liverpool L3 5QA, UK; ${ }^{2}$ Brock University, Department of Biological Sciences, St. Catharines, L2S 3 A1, Canada; ${ }^{3}$ Liverpool School of Tropical Medicine, Centre for Drugs and Diagnostics, Liverpool, L3 5QA, UK; ${ }^{4}$ Unilever Research and Development, Port Sunlight CH63 $3 \mathrm{JW}$, UK; ${ }^{5}$ Unilever Research and Development Centre, Bangalore 560066, India.

*Correspondence: Michael Hoptroff, michael.hoptroff@unilever.com; Grant L. Hughes, Grant.Hughes@lstmed.ac.uk

Keywords: SARS-CoV-2; COVID-19; mouthwash; saliva; oral hygiene.

Abbreviations: ACE-2, angiotensin-converting enzyme 2; ASTM, American Society for Testing and Materials; CHX, chlorhexidine; CPC, cetyl pyridinium chloride; DMEM, Dulbecco's minimal essential medium; FBS, foetal bovine serum; LOD, limit of detection; p.f.u., plaque forming units; QACS,

quaternary ammonium compounds. 
Methodology. Inactivation of SARS-CoV-2 variants by mouthwash formulations in the presence or absence of human saliva was assayed using ASTM International Standard E1052-20 methodology.

Results. Appropriately formulated mouthwashes containing $0.07 \%$ cetylpyridinium chloride but not $0.2 \%$ chlorhexidine completely inactivated SARS-CoV-2 (USA-WA1/2020, Alpha, Beta, Gamma, Delta) up to the limit of detection in suspension assays. Tests using USA-WA1/2020 indicates that efficacy is maintained in the presence of human saliva.

Conclusions. Together these data suggest cetylpyridinium chloride-based mouthwashes are effective at inactivating SARSCoV-2 variants. This indicates potential to reduce viral load in the oral cavity and mitigate transmission via salivary aerosols.

\section{INTRODUCTION}

The high viral load of SARS-CoV-2 present in the saliva of infected individuals [1] and in aerosol droplets formed passively during speech and breathing, and actively during coughing [2-4] have contributed to the recognition that saliva plays a key role in the transmission of SARS-CoV-2 [5-7]. The potential of the oral cavity to act as a viral reservoir is supported by the presence of the angiotensin-converting enzyme 2 (ACE-2) receptor in oral gingival epithelia and salivary glands and the infection of these tissues by SARS-CoV-2 in vivo [8], potentially aggravating systemic infection via an oral-vasculo-pulmonary route [9].

The use of oral rinses or mouthwashes have been proposed by health organizations to mitigate transmission of SARS-CoV-2 during dentistry procedures due to their demonstrated efficacy in inactivating SARS-CoV-2 in vitro and in vivo [10-12]. The antimicrobial action of a mouthwash is dependent on a combination of the active ingredients, their intrinsic efficacy and their bioavailability during use. Active ingredients used in mouthwashes include quaternary ammonium compounds (QACS) such as dequalinium chloride, benzalkonium chloride, cetyl pyridinium chloride (CPC) and chlorhexidine (CHX), which are believed to function as antimicrobials via a stepwise process of charge-mediated attraction and destabilisation of the bacterial lipid envelope [13-15].

CPC is widely used in mouthwash formulations displaying substantive action against a range of oral bacteria [16-18] and viruses, including SARS-CoV-2 [10, 19-21], whilst data on virucidal efficacy of CHX against SARS-CoV-2 has been more varied [22-26]. All mouthwashes, regardless of composition, must function in situ in the oral cavity, and hence must retain efficacy in the presence of human saliva, overcoming any potential deactivation from salivary components [27-29].

To investigate the impact of mouthwash composition on efficacy we compared the in vitro virucidal efficacy of mouthwashes containing $0.07 \% \mathrm{CPC}$ and $0.2 \% \mathrm{CHX}$ digluconate against a range of SARS-CoV-2 variants. In addition, the efficacy of a representative CPC containing mouthwash was also investigated in the presence of human saliva. Our findings suggest CPC mouthwashes offer potent virucidal activity that is effective against all variants tested and which is maintained in the presence of human saliva under simulated usage conditions.

\section{METHODS}

\section{Cell culture and viruses}

Vero E6 cells (C1008: African green monkey kidney cells) obtained from Public Health England, were maintained in Dulbecco's minimal essential medium (DMEM) with $10 \%$ foetal bovine serum (FBS) and $0.05 \mathrm{mg} \mathrm{ml}^{-1}$ gentamicin. Cells were maintained at $37^{\circ} \mathrm{C}$ and $5 \% \mathrm{CO} 2$. The following reagents were obtained through BEI Resources, NIAID, NIH: SARS-Related Coronavirus 2, Isolate USA-WA1/2020, NR-52281; SARS-Related Coronavirus 2, Isolate hCoV-19/England/204820464/2020, NR-54000, contributed by Bassam Hallis; SARS-Related Coronavirus 2, Isolate hCoV-19/South Africa/KRISP-EC-K005321/2020, NR-54008, contributed by Alex Sigal and Tulio de Oliveira; SARS-Related Coronavirus 2, Isolate hCoV-19/Japan/TY7-503/2021 (Brazil P.1), NR-54982, contributed by National Institute of Infectious Diseases. The viruses were obtained as passage 5 of SARS-CoV-2 isolate (USA-WA1/2020) and passage 2 or 3 of Alpha (hCoV-19/England/204820464/2020), Beta (hCoV-19/South Africa/KRISPEC-K005321/2020) and Gamma (hCoV-19/Japan/TY7-503/2021). The Delta variant was passage 5 of a clinically isolated strain (SARS-CoV-2/human/GBR/Liv_273/2021, GenBank accession OK392641). Variants were cultured in Vero E6 cells maintained in DMEM with $4 \% \mathrm{FBS}$ and $0.05 \mathrm{mg} \mathrm{m}^{-1}$ gentamicin at $37^{\circ} \mathrm{C}$ and $5 \% \mathrm{CO} 2$. Then, $48 \mathrm{~h}$ post-inoculation, virus was harvested and stored at $-80^{\circ} \mathrm{C}$ until used. All SARS-CoV-2 work was conducted in a containment level 3 laboratory.

\section{Preparation of saliva}

Stimulated saliva was collected at Unilever Research Port Sunlight during November 2019 from six donors over 2 days. Healthy donors, three male, three female, age 18-60 years old, provided a stimulated daytime saliva sample for which they were given a piece of gum to chew (Wrigley's Turbulence) [30]. Subjects were given a maximum of five sterile $30 \mathrm{ml}$ containers in which they were asked to provide a $20-25 \mathrm{ml}$ sample of saliva per container. Subjects were requested to leave $30 \mathrm{~min}$ after eating or drinking before providing a saliva sample. 
Table 1. Mouthwash formulations examined for SARS-CoV-2 inactivation

\begin{tabular}{|lr|}
\hline Treatment & Code \\
\hline Proprietary commercially available formulation containing $0.07 \% \mathrm{CPC}$ with flavour and mix of herbal extracts (0\% ethanol) & MW-A \\
Proprietary commercially available formulation containing $0.07 \% \mathrm{CPC}$ with flavour & MW-B \\
$(0 \%$ ethanol) & MW-C \\
$0.2 \% \mathrm{CHX}$ digluconate with flavour (7\% ethanol) & Positive control \\
$70 \%$ ethanol in distilled water & Negative control \\
Distilled water & \\
\hline
\end{tabular}

CHX, Chlorhexidine; CPC, cetyl pyridinium chloride.

The collected samples were stored overnight at $4^{\circ} \mathrm{C}$. A second collection from the same subjects was performed on the following day and the saliva from day 1 and day 2 was pooled together, decanted into bottles and stored at $-80^{\circ} \mathrm{C}$ prior to gamma irradiation (Systagenix, UK, Cobolt 60 turntable, dose rate $1.2 \mathrm{kGy} / \mathrm{h}$, minimum dose $32.1 \mathrm{kGy}$ ) sufficient to achieve sterilization [31]. After sterilization saliva was stored in sealed bottles at $4{ }^{\circ} \mathrm{C}$ prior to testing.

\section{Virus inactivation by different mouthwash formulations}

Mouthwash formulations (Table 1 and Fig. 1) were assessed following the ASTM International Standard E1052-20 [32]. Briefly, $900 \mu \mathrm{l}$ of mouthwash formulation was added to $100 \mu \mathrm{l}$ of virus suspension (SARS-CoV-2, USA-WA1/2020), containing $4 \%$ FBS and incubated for $30 \mathrm{~s}$. After the $30 \mathrm{~s}$ incubation, $9 \mathrm{ml}$ of Dey and Engley neutralizing broth (DE broth) was added and $25 \mu \mathrm{l}$ of the sample was transferred into a dilution series for quantification. The viral inoculum was quantified before each experiment. All experiments were carried out in triplicates. SARS-CoV-2 titre was calculated using standard plaque assays as previously described [33]. Briefly, samples were serially diluted in DMEM containing 2\% FBS and incubated with Vero cells for $1 \mathrm{~h}$. After incubation, an overlay with DMEM $2 \%$ FBS, $0.1 \%$ gentamycin and $0.4 \%$ agarose was applied to the cells. The cells were allowed to incubate for $72 \mathrm{~h}$ at $37^{\circ} \mathrm{C}$ with $5 \% \mathrm{CO}_{2}$. After incubation, the cells were fixed with $10 \%$ formalin solution, and stained with $0.25 \%$ Crystal Violet.

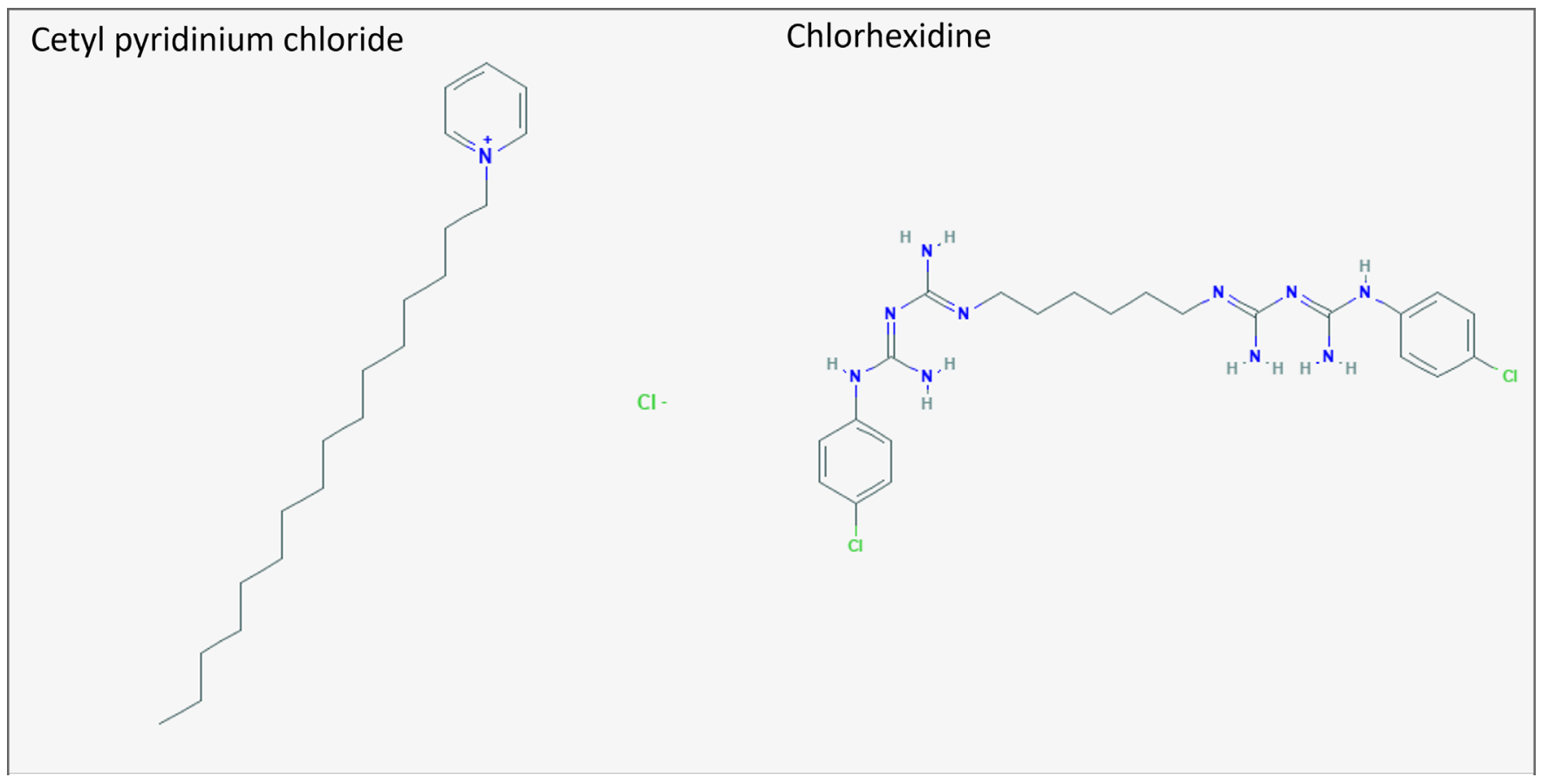

Fig. 1. Structures of cetylpyridinium chloride (CPC) and chlorhexidine (CHX). 


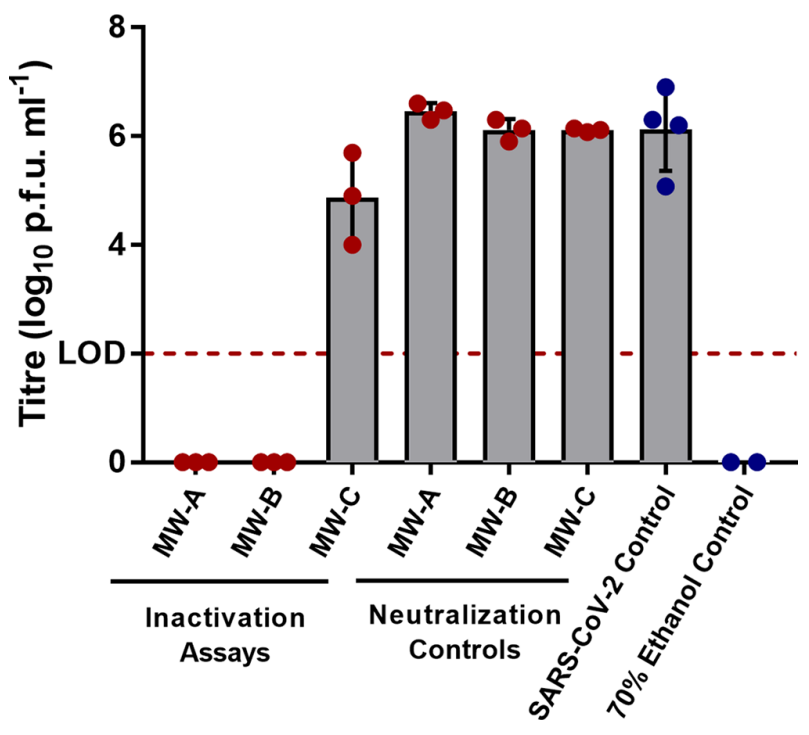

Fig. 2. Mouthwash formulas were tested for virucidal action against SARS-CoV-2 (USA-WA1/2020). Mouthwashes were incubated with SARS-CoV-2 inoculum for $30 \mathrm{~s}$. Both MW-A and MW-B reduced to below the LOD, while MW-C reduced viral titre by $1.26 \log _{10}$ p.f.u. $\mathrm{ml}^{-1}$ compared to the water control. $L O D=2.0 \log _{10}$ p.f.u. $\mathrm{ml}^{-1}$. Viral titres recovered from the water control averaged $6.12 \log _{10}$ p.f.u. $\mathrm{ml}^{-1}$, while viral titre recovered from neutralization controls were within $1.0 \log _{10}$ p.f.u. $\mathrm{ml}^{-1}$ indicating all virucidal activity occurred within $30 \mathrm{~s}$ of incubation. LOD $\left(2.0 \log _{10}\right.$ p.f.u. $\left.\mathrm{ml}^{-1}\right)$ is shown across the graph with a dotted red line. Error bars represent standard deviation of triplicates, while red dots are experimental data values and blue dots control values.

\section{Virus inactivation by mouthwash in the presence of saliva}

To assess if human saliva alters the effectiveness of CPC mouthwash, $800 \mu \mathrm{l}$ of $\mathrm{MW}$-B mouthwash formula was added to $100 \mu \mathrm{l}$ of human saliva mixed with $100 \mu \mathrm{l}$ of SARS-CoV-2 (USA-WA1/2020) inoculum. The solution was incubated for $30 \mathrm{~s}$ and $9 \mathrm{ml}$ of DE broth was added. As a control, $800 \mu \mathrm{l}$ of MW-B mouthwash formula was added to $100 \mu \mathrm{l}$ of sterile water and $100 \mu \mathrm{l}$ of virus inoculum, with $9 \mathrm{ml}$ of $\mathrm{DE}$ broth added after $30 \mathrm{~s}$ of incubation. Experiments were carried out in duplicate.

\section{Saliva, neutralization, and cytotoxicity assays}

To assess if human saliva has inherent virucidal action against SARS-CoV-2 (USA-WA1/2020) $100 \mu \mathrm{l}$ of virus inoculum was added to either $800 \mu \mathrm{l}$ of sterile water and $100 \mu \mathrm{l}$ of irradiated human saliva (dilute saliva), or $900 \mu \mathrm{l}$ of irradiated human saliva (neat saliva) for a $5 \mathrm{~min}$ incubation. After $5 \mathrm{~min}$ had elapsed, a $25 \mu \mathrm{l}$ sample was placed into a dilution series. Neutralization and cytotoxicity assays were performed following the ASTM International Standard E1052-20 [32]. Briefly, neutralization controls were carried out by adding $9 \mathrm{ml}$ of DE broth to $900 \mu \mathrm{l}$ of mouthwash formula. To this, $100 \mu \mathrm{l}$ of virus suspension was added for $30 \mathrm{~s}$ and $25 \mu \mathrm{l}$ removed to a dilution series. Samples $(25 \mu \mathrm{l})$ from each condition were serial diluted tenfold and quantified via a standard plaque assay. Plaques were counted to determine viral titre. To determine the cytotoxicity of the mouthwashes, $100 \mu \mathrm{l}$ of $4 \%$ DMEM was added to $900 \mu \mathrm{l}$ of test mouthwash formula for $30 \mathrm{~s}$. To this $9 \mathrm{ml}$ of DE broth was added and $25 \mu \mathrm{l}$ placed into dilution series. Samples $(25 \mu \mathrm{l})$ from each dilution were processed by standard plaque assay and cell viability was evaluated at day 3 post-inoculation. All experiments were carried out in triplicate.

\section{RESULTS}

\section{Comparison of CPC- and $\mathrm{CHX}$ containing mouthwashes}

We tested the ability of CPC and CHX to inactivate SARS-CoV-2 (USA-WA1/2020). Following a $30 \mathrm{~s}$ incubation in the presence of the test mouthwashes a reduction in viral titre of $\geq 4.0 \log _{10}$ p.f.u. $\mathrm{ml}^{-1}$ was observed with $\mathrm{MW}-\mathrm{A}$ and $\mathrm{MW}$-B and of $<2.0 \log _{10}$ p.f.u. $\mathrm{ml}^{-1}$ for $\mathrm{MW}$-C. No reduction of viral titre occurred in the water control and however complete inactivation was observed by the $70 \%$ ethanol control. All treatments were effectively neutralized by the addition of DE broth (Fig. 2). Cytotoxicity assays showed no cytopathic effect of the mouthwashes on Vero E6 cells at the dilutions tested. The limit of detection (LOD of the assay was $2.0 \log _{10}$ p.f.u. $\mathrm{ml}^{-1}$. 
Table 2. Mouthwash formulas that were proven to work against SARS-CoV-2 (USA-WA1/2020) were then tested against Alpha, Beta, and Gamma and Delta variants of SARS-CoV-2. Both MW-A and MW-B were able to reduce the viral titre of all three variants to below the limit of detection (2.0log ${ }_{10}$ p.f.u. $\mathrm{ml}^{-1}$ ) within $30 \mathrm{~s}$

\begin{tabular}{|c|c|c|c|c|}
\hline \multirow[b]{2}{*}{ Variant } & \multirow[b]{2}{*}{ Pango lineage } & \multicolumn{3}{|c|}{ Average titre $\left(\log _{10}\right.$ p.f.u. $\left.\mathrm{ml}^{-1}\right)$ Reduction } \\
\hline & & MW-A & MW-B & $70 \%$ ethanol \\
\hline Alpha & B.1.1.7 & 3.11 & 3.11 & 3.11 \\
\hline Beta & B.1.351 & 4.11 & 4.11 & 4.11 \\
\hline Gamma & $\mathbf{P . 1}$ & 3.36 & 3.36 & 3.36 \\
\hline Delta & B.1.617.2 & 4.52 & 4.52 & 4.52 \\
\hline
\end{tabular}

p.f.u., plaque forming units.

\section{Inactivation of SARS-CoV-2 variants by test products}

We also tested the ability of CPC and CHX to inactivate SARS-CoV-2 variants of concern, Alpha, Beta, Gamma and Delta. Following the $30 \mathrm{~s}$ incubation of Alpha with MW-A and MW-B an average reduction of $3.11 \log _{10}$ p.f.u. $\mathrm{ml}^{-1}$ to below the LOD was seen. Incubation of Beta with test products saw an average reduction of $4.1 \log _{10}$ p.f.u. $\mathrm{ml}^{-1}$, Gamma saw an average reduction of 3.36 $\log _{10}$ p.f.u. $\mathrm{ml}^{-1}$, and Delta saw an average reduction of $4.52 \log _{10}$ p.f.u. $\mathrm{ml}^{-1}$, all below the LOD (Table 2). In assays carried out with the variants, no reduction was seen in the water control and reduction below the LOD was seen in the $70 \%$ ethanol control. The ability to achieve a $4.0 \log _{10}$ p.f.u. $\mathrm{ml}^{-1}$ in the variant assays was dependent on titres of SARS-CoV-2 variants following standard propagation methods.

\section{Testing in the presence of human saliva}

Under normal usage mouthwashes must be functional in the presence of human saliva, hence investigations were undertaken to assess whether saliva displays any measurable endogenous virucidal activity against SARS-CoV-2 (USA-WA1/2020) and to assess whether saliva acts as an inhibitory 'soil' quenching the virucidal function of mouthwash formulations. The endogenous virucidal activity of neat and dilute human saliva was measured over a contact time of $5 \mathrm{~min}$ (Fig. 3a) during which no significant reduction in viral load was observed compared to the water control. Viral titres of $5.70 \log _{10}$ p.f.u. $\mathrm{ml}^{-1}, 5.6 \log _{10}$ p.f.u. $\mathrm{ml}^{-1}$ and
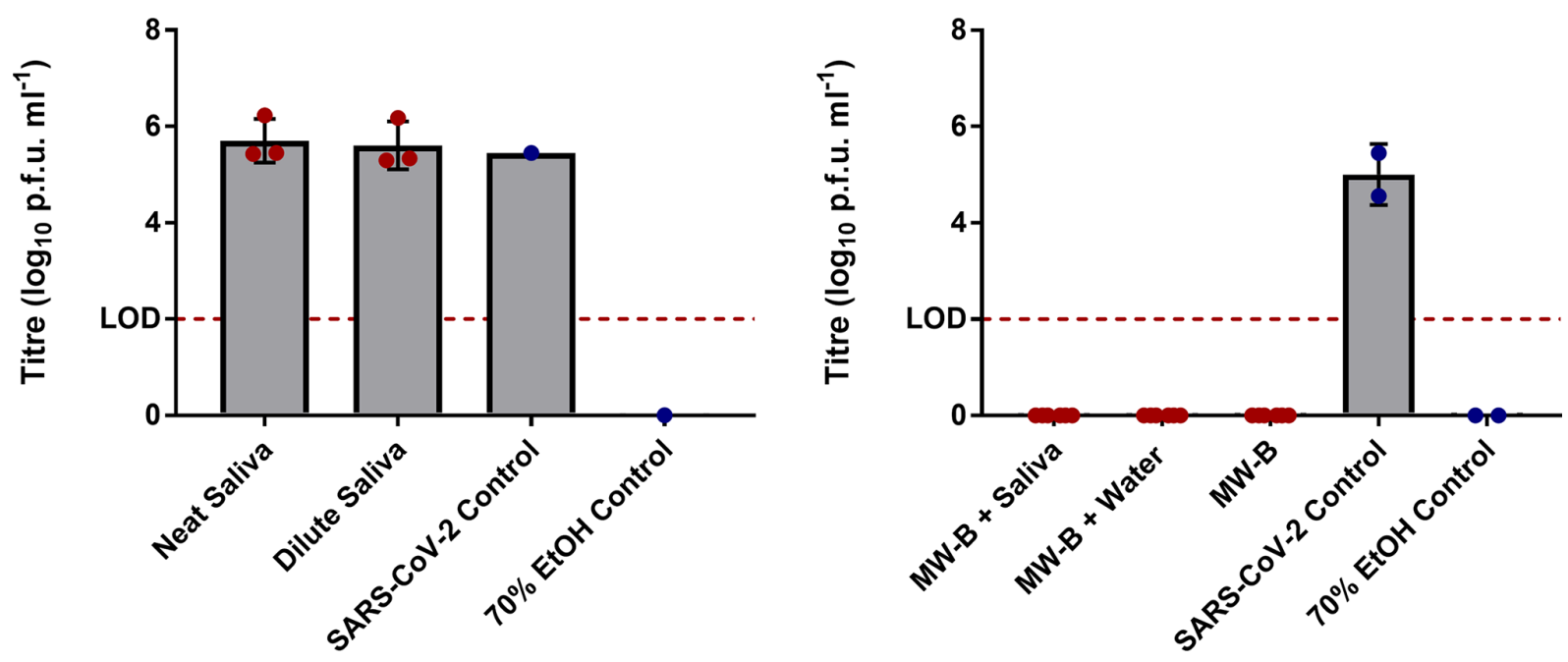

Fig. 3. Irradiated human saliva has no effect upon the viral titre of SARS-CoV-2 as compared to the water control after incubation with inoculum for $5 \mathrm{~min}$. Neat saliva had a ratio of eight parts water to one-part irradiated human saliva to one-part virus inoculum, while dilute saliva had a ratio nine parts irradiated human saliva to one-part virus inoculum (a). Human saliva does not inhibit the virucidal activity of mouthwash formulas proven to reduce the titre of SARS-CoV-2. MW-B was able to reduce viral titre to below the LOD both in the presence of irradiated human saliva and without. Human saliva was added in a ratio of eight parts MW-B to one-part irradiated human saliva to one-part virus inoculum (b). LOD (2.0log ${ }_{10}$ p.f.u. ml $^{-1}$ ) is shown across both graphs with a dotted red line. Error bars represent standard deviation, while red dots are experimental data values and blue dots control values. 
5.45 $\log _{10}$ p.f.u. $\mathrm{ml}^{-1}$ were recovered from the neat saliva, dilute saliva incubation and the water control, respectively. It is essential that mouthwashes maintain efficacy in the presence of human saliva. To investigate this, we examined if the virucidal efficacy of MW-B was altered by saliva. We found that MW-B was still capable of inactivation of SARS-CoV-2 to below the LOD in the presence of saliva, indicating that CPC retained efficacy despite the soil load (Fig. 3b).

\section{DISCUSSION}

Our results confirm that mouthwash formulations containing $0.07 \%$ CPC, inactivate SARS-CoV-2 by up to $99.99 \%$, representing a value below the LOD after a contact time of $30 \mathrm{~s}$. In contrast, a mouthwash containing CHX ( $0.2 \%$ chlorhexidine gluconate), exhibited poorer virucidal activity against SARS-CoV-2. Our observations are consistent with others, where multiple different CPC mouthwash formulations have been shown to effectively inactivate SARS-CoV-2 in vitro, whereas CHX containing mouthwashes are reported to have modest ability to inactive SARS-CoV-2 $[10,25,34]$. The virucidal action of CPC mouthwash was maintained in the presence of whole human saliva, consistent with human clinical trials, which report that rinsing with CPC mouthwash can lower SARS-CoV-2 salivary count for several hours after use [11,35].

Over the course of the global pandemic, several SARS-CoV-2 variants have emerged with mutations changing the amino acid sequence of the receptor-binding domain of the spike protein [36]. Four variants of concern, Alpha, Beta, Gamma and Delta [37], were effectively inactivated within $30 \mathrm{~s}$ by both $0.07 \% \mathrm{CPC}$ mouthwashes, with a reduction in viral titre below the LOD and equivalent to the $70 \%$ ethanol control. As the CPC molecule disrupts the viral lipid envelope and the membrane is unchanged by mutations, our data supports the likely efficacy of CPC mouthwash in reducing viral load irrespective of the SARS-CoV-2 variant. It is interesting to note, as highlighted in Table 2, that SARS-CoV-2 variants displayed reproducible differences in titre. Although elucidating the exact mechanisms underpinning this observation are beyond the scope of this report, recent work [38] has suggested that natural variations in the SARS-CoV-2 viral accessory protein, ORF3a and non-structural protein, NSP2, may impact infectivity in laboratory models and we believe further investigation of such effects would assist the global response to the current pandemic.

Recently the oral cavity has been proposed to have a direct role in COVID-19 disease severity based on a proposed oral-vasculopulmonary infection route. Poor oral hygiene with plaque build-up, subsequent gingivitis and periodontitis facilitates direct entry of the virus via the oral gingival sulcus and periodontal pockets enabling infection of the circulatory system and lungs [9]. CPC mouthwashes with anti-plaque and virucidal activity against SARS-CoV-2 could have the potential to lower viral count and lessen the risk of severe lung disease in COVID-19 patients.

In conclusion, two mouthwashes containing $0.07 \% \mathrm{CPC}$ were effective at inactivating SARS-CoV-2, within $30 \mathrm{~s}$ with greater than 4. $0 \log _{10}$ p.f.u. $\mathrm{ml}^{-1}$ reduction in viral titre. Moreover, virucidal activity of CPC was maintained in the presence of whole human saliva. Both $0.07 \%$ CPC mouthwashes were as effective as $70 \%$ ethanol against four variants of concern; Alpha, Beta, Gamma and Delta suggesting these CPC formulations possess virucidal action against all variants. In contrast, under the same experimental conditions, a mouthwash containing $0.2 \%$ chlorhexidine digluconate did not have substantial action against SARS-CoV-2 in vitro. Given the ongoing global pandemic, and the recognition of the significance of the oral cavity in infection, transmission and disease severity, daily use of an effective CPC mouthwash as part of a good oral hygiene routine, could be a low-cost and simple measure to reduce transmission risk.

Funding information

Funding for this work and was provided by Unilever.

\section{Acknowledgements}

Unilever funded this study and supplied mouthwash formulations. Carole Philpotts (Unilever) is thanked for her assistance in supply of saliva. E.I.P. and G.L.H. were supported by the EPSRC (V043811/1) and UKRI-BBSRC COVID rolling fund (BB/V017772/1). G.L.H. was also supported by the BBSRC (BB/T001240/1 and BB/V011278/1), a Royal Society Wolfson Fellowship (RSWF 1 1 1180013), the NIH (R21Al138074), the EPSRC (EP/V043811/1), the UKRI (20197 and 85336), and the NIHR (NIHR2000907). G.L.H. is affiliated to the National Institute for Health Research Health Protection Research Unit (NIHR HPRU) in Emerging and Zoonotic Infections at University of Liverpool in partnership with Public Health England (PHE), in collaboration with Liverpool School of Tropical Medicine and the University of Oxford. G.L.H. is based at LSTM. The views expressed are those of the author(s) and not necessarily those of the NHS, the NIHR, the Department of Health or Public Health England. USA-WA1/2020 was deposited by the Centre's for Disease Control and Prevention and obtained through BEI Resources. NIAID, NIH: SARS-Related Coronavirus 2, Isolate, NR-52281. B.1.1.7, Alpha (hCoV-19/ England/204820464/2020) was obtained through BEI Resources, NIAID, NIH: SARS-Related Coronavirus 2, Isolate hCoV-19/England/204820464/2020, NR-54000, contributed by Bassam Hallis. B.1.351, Beta (hCoV-19/South Africa/KRISP-EC-K005321/2020) was obtained through BEl Resources, NIAID, $\mathrm{NIH}$ : SARS-Related Coronavirus 2, Isolate hCoV-19/South Africa/KRISP-EC-K005321/2020, NR-54008, contributed by Alex Sigal and Tulio de Oliveira. P.1, Gamma (hCoV-19/Japan/TY7-503/2021) was obtained through BEI Resources, NIAID, NIH: SARS-Related Coronavirus 2, Isolate hCoV-19/Japan/ TY7-503/2021 (Brazil P.1), NR-54982, contributed by National Institute of Infectious Diseases.

Conflicts of interest

A.G., S.M. and M.H. are employees of Unilever. 
Ethical statement

Ethical approval for saliva collection from the Unilever R\&D Port Sunlight Independent Ethics Committee (GEN 022 13). All individuals gave informed consent to participate in the study. Appropriate consent was obtained from all participants/subjects in this research.

References

1. To KK-W, Tsang OT-Y, Leung W-S, Tam AR, Wu T-C, et al. Temporal profiles of viral load in posterior oropharyngeal saliva samples and serum antibody responses during infection by SARS-CoV-2: an observational cohort study. Lancet Infect Dis 2020;20:565-574.

2. Zuo YY, Uspal WE, Wei T. Airborne transmission of COVID-19: aerosol dispersion, lung deposition, and virus-receptor interactions. ACS Nano 2020;14:16502-16524.

3. Fennelly KP. Particle sizes of infectious aerosols: implications for infection control. Lancet Respir Med 2020;8:914-924.

4. Stadnytskyi V, Bax CE, Bax A, Anfinrud P. The airborne lifetime of small speech droplets and their potential importance in SARS-CoV-2 transmission. Proc Natl Acad Sci U S A 2020;117:11875-11877.

5. Li Y, Ren B, Peng X, Hu T, Li J, et al. Saliva is a non-negligible factor in the spread of COVID-19. Mol Oral Microbiol 2020;35:141-145.

6. World Health 0. Modes of transmission of virus causing COVID-19: implications for IPC precaution recommendations: scientific brief, 29 March 2020. Geneva: World Health Organization2020 2020 Contract No.: WHO/2019-nCoV/Sci_Brief/Transmission_modes/2020.2; 2020

7. To KK-W, Tsang OT-Y, Yip CC-Y, Chan K-H, Wu T-C, et al. Consistent detection of 2019 novel coronavirus in Saliva. Clin Infect Dis 2020;71:841-843

8. Huang N, Pérez P, Kato T, Mikami Y, Okuda K, et al. SARS-CoV-2 infection of the oral cavity and saliva. Nat Med 2021;27:892-903.

9. Lloyd-Jones G, Molayem S, Cruvinel Pontes C, Chapple I. The COVID-19 pathway: a proposed oral-vascular-pulmonary route of SARS-CoV-2 infection and the importance of oral healthcare measures. Journal of Oral Medicine and Dental Research $2021 ; 2: 1-23$

10. Statkute E, Rubina A, O'Donnell VB, Thomas DW, Stanton RJ. Brief report: the virucidal efficacy of oral rinse components against SARS-CoV-2 in vitro. bioRxiv 2011:381079.

11. Eduardo F de P, Corrêa L, Heller D, Daep CA, Benitez C, et al. Salivary SARS-CoV-2 load reduction with mouthwash use: $A$ randomized pilot clinical trial. Heliyon 2021;7:e07346.

12. Burton MJ, Clarkson JE, Goulao B, Glenny A-M, McBain AJ, et al. Antimicrobial mouthwashes (gargling) and nasal sprays administered to patients with suspected or confirmed COVID-19 infection to improve patient outcomes and to protect healthcare workers treating them. Cochrane Database Syst Rev 2020;9:CD013627

13. McDonnell G, Russell AD. Antiseptics and disinfectants: activity, action, and resistance. Clin Microbiol Rev 1999;12:147-179.

14. Gilbert P, Moore LE. Cationic antiseptics: diversity of action under a common epithet. J Appl Microbiol 2005;99:703-715.

15. Salton MR. Lytic agents, cell permeability, and monolayer penetrability. J Gen Physiol 1968;52:227Suppl - 52s.

16. Teng F, He T, Huang S, Bo C-P, Li Z, et al. Cetylpyridinium chloride mouth rinses alleviate experimental gingivitis by inhibiting dental plaque maturation. Int J Oral Sci 2016:8:182-190.

17. Kozak KM, Gibb R, Dunavent J, White DJ. Efficacy of a high bioavailable cetylpyridinium chloride mouthrinse over a 24-hour period: a plaque imaging study. Am J Dent 2005;18 Spec No:18A-23A.

18. Cummins D, Creeth JE. Delivery of antiplaque agents from dentifrices, gels, and mouthwashes. J Dent Res 1992;71:1439-1449.

19. O'Donnell VB, Thomas D, Stanton R, Maillard J-Y, Murphy RC, et al. Potential role of oral rinses targeting the viral lipid envelope in SARS-CoV-2 Infection. Function (Oxf) 2020;1:zqaa002.
20. Baker N, Williams AJ, Tropsha A, Ekins S. Repurposing quaternary ammonium compounds as potential treatments for COVID-19. Pharm Res 2020;37:104.

21. Muñoz-Basagoiti J, Perez-Zsolt D, León R, Blanc V, Raïch-Regué D et al. Mouthwashes with CPC Reduce the Infectivity of SARS-CoV-2 Variants In Vitro. J Dent Res 2021;100:1265-1272.

22. Xu C, Wang A, Hoskin ER, Cugini C, Markowitz K, et al. Differential effects of antiseptic mouth rinEffects of Antiseptic Mouth Rinses on SARS-CoV-2 infectivity in vinfectivity In Vitro. Pathogens 2021;10:272.

23. Davies K, Buczkowski H, Welch SR, Green N, Mawer D, et al. Effective in vitro inactivation of SARS-CoV-2 by commercially available mouthwashes. J Gen Virol 2021;102:001578.

24. Koch-Heier J, Hoffmann H, Schindler M, Lussi A, Planz O. Inactivation of SARS-CoV-2 through treatment with the mouth rinsing solutions ViruProX ${ }^{\circledR}$ and Bacter $X^{\circledR}$ Pro. Microorganisms 2021;9:521.

25. Komine A, Yamaguchi E, Okamoto N, Yamamoto K. Virucidal activity of oral care products against SARS-CoV-2 in vitro. J Oral Maxillofac Surg Med Pathol 2021;33:475-477.

26. Meister TL, Brüggemann Y, Todt D, Conzelmann C, Müller JA, et al. Virucidal efficacy of different oral rinses against severe acute respiratory syndrome coronavirus 2. J Infect Dis 2020;222:1289-1292.

27. Kulkarni BV, Wood KV, Mattes RD. Quantitative and qualitative analyses of human salivary NEFA with gas-chromatography and mass spectrometry. Front Physiol 2012;3:328.

28. Chen Z, Feng S, Pow EHN, Lam OLT, Mai S, et al. Organic anion composition of human whole saliva as determined by ion chromatography. Clin Chim Acta 2015:438:231-235.

29. Garcia-Godoy F, Klukowska MA, Zhang YH, Anastasia K, Cheng $\mathrm{R}$, et al. Comparative bioavailability and antimicrobial activity of cetylpyridinium chloride mouthrinses in vitro and in vivo. Am J Dent 2014;27:185-190.

30. Dawes C, Tsang RW, Suelzle T. The effects of gum chewing, four oral hygiene procedures, and two saliva collection techniques, on the output of bacteria into human whole saliva. Arch Oral Biol 2001;46:625-632.

31. Ruhl S, Berlenbach P, Langenfelder S, Hörl D, Lehn N, et al. Integrity of proteins in human saliva after sterilization by gamma irradiation. Appl Environ Microbiol 2011;77:749-755.

32. ASTM. ASTM International E1052-20, Standard Practice to Assess the Activity of Microbicides against Viruses in Suspension. West Conshohocken, PA, 2020.

33. Anderson ER, Hughes GL, Patterson El. Inactivation of SARS-CoV-2 on surfaces and in solution with Virusend (TX-10), a novel disinfectant. Access Microbiol 2021;3:000228.

34. Davies K, Buczkowski H, Welch SR, Green N, Mawer D, et al. Effective in vitro inactivation of SARS-CoV-2 by commercially available mouthwashes. J Gen Virol 2021;102.

35. Seneviratne CJ, Balan P, Ko KKK, Udawatte NS, Lai D, et al. Efficacy of commercial mouth-rinses on SARS-CoV-2 viral load in saliva: randomized control trial in Singapore. Infection 2021;49:305-311.

36. Harvey WT, Carabelli AM, Jackson B, Gupta RK, Thomson EC, et al. SARS-CoV-2 variants, spike mutations and immune escape. Nat Rev Microbiol 2021;19:409-424.

37. Konings F, Perkins MD, Kuhn JH, Pallen MJ, Alm EJ, et al. SARSCoV-2 Variants of Interest and Concern naming scheme conducive for global discourse. Nat Microbiol 2021;6:821-823.

38. Pohl MO, Busnadiego I, Kufner V, Glas I, Karakus U, et al. SARSCoV-2 variants reveal features critical for replication in primary human cells. PLoS Biol 2021;19:e3001006. 